\title{
O PAULISTANO NO MAPA SOCIOLINGUÍSTICO BRASILEIRO
}

\author{
Ronald Beline MENDES * \\ Livia OUSHIRO **
}

- RESUMO: Este artigo traz notícia acerca dos trabalhos que vêm sendo desenvolvidos pelo Grupo de Estudos e Pesquisa em Sociolinguística da USP (GESOL-USP). Com o intuito de tornar a cidade de São Paulo e o paulistano mais presentes no mapa da sociolinguística brasileira, esses trabalhos organizam-se, sobretudo, em torno da construção de uma nova amostra da fala paulistana, que permita responder às seguintes perguntas centrais: "o que significa falar como paulistano?" e "quais são as variáveis e variantes linguísticas que o identificam?". Essa nova amostra (SP2010) será disponibilizada (áudio e transcrições) para acesso público e para fins de pesquisa em página própria na Internet. Além de discutir os critérios que definem a construção de tal amostra, bem como os desafios nela envolvidos, esse artigo também faz um panorama dos trabalhos que se têm desenvolvido a partir dos dados que foram coletados durante a fase de preparação e de treinamento de jovens pesquisadores que nela trabalhariam (Amostra SP-Piloto). Finalmente, também delineia caminhos para trabalhos futuros dentro da agenda de pesquisa do grupo.

- PALAVRAS-CHAVE: Variação linguística. Paulistanos. Identidade. Corpus.

\section{Introdução}

De uma perspectiva internacional, pode-se dizer que a Sociolinguística é um campo de estudos bastante desenvolvido no Brasil. Na reedição de um de seus trabalhos seminais e mais conhecidos, Labov (2006) coloca ao lado de Nova Iorque algumas cidades ao redor do mundo nas quais foram desenvolvidos projetos de pesquisa que considera de impacto na área de estudos de variação linguística, sobretudo em termos de comunidades urbanas. Entre elas aparecem Rio de Janeiro, Belo Horizonte e São Paulo - esta última, o centro urbano que o presente artigo focaliza.

Nas palavras do próprio autor, sua lista é "inevitavelmente parcial" (LABOV, 2006); no caso brasileiro, além da importância dos trabalhos do PEUL, vale lembrar

\footnotetext{
* USP - Universidade de São Paulo. Faculdade de Filosofia, Letras e Ciências Humanas. São Paulo - SP - Brasil. 05508-010 - rbeline@usp.br

** USP - Universidade de São Paulo. Faculdade de Filosofia, Letras e Ciências Humanas. São Paulo - SP - Brasil. 05508-010 - livia.oushiro@usp.br
} 
aqueles desenvolvidos no interior de projetos como o VARSUL, oVALPB e o ALIP, ${ }^{1}$ entre vários outros. Em cada um deles, variedades regionais e sociais do Brasil vêm sendo extensivamente descritas através de várias publicações, na forma de artigos, dissertações e livros, entre os quais podem ser citados Callou, Moraes (1996), Monaretto (1997) e Hora (2004).

Pode-se dizer que São Paulo, contudo, é um centro urbano ainda pouco estudado sociolinguisticamente. Embora o português paulistano já tenha sido documentado e analisado através de importantes projetos de pesquisa, tais como o Projeto NURC-SP (CASTILHO; PRETI, 1986, 1987; PRETI; URBANO, 1998, 1990), o Projeto Para a História do Português Paulista (CASTILHO, 2007) e o Projeto Para a História do Português Brasileiro (CASTILHO, 2010), foram poucos os estudos, até recentemente, que tenham conceitualizado o falante paulistano sociolinguisticamente, enquanto membro de uma comunidade com características específicas, e que tenham se preocupado com a relação entre usos linguísticos e diferentes identidades sociais.

Devem ser lembrados aqui os trabalhos de Rodrigues (1987) e Coelho (2006). A primeira estudou a variação na concordância verbal em uma amostra de fala de 40 informantes analfabetos ou semialfabetizados de uma favela paulistana - amostra esta que incluiu não somente indivíduos paulistanos, mas também indivíduos provenientes de outras localidades do estado e do país. Neste sentido, além de vários outros interesses sociolinguísticos, pode-se dizer que Rodrigues (1987) é um dos poucos trabalhos que organiza uma amostra do português falado na cidade de São Paulo (ainda que circunscrito localmente numa favela) com objetivos variacionistas. O segundo investigou a variação no emprego dos pronomes de primeira pessoal do plural, bem como a concordância verbal com "nós", em uma amostra de 24 entrevistas que o pesquisador pôde coletar, também numa favela paulistana, graças ao seu trabalho de observação etnográfica: visitou com frequência a comunidade e deu-se conta de que, ali, os indivíduos se organizavam em grupos cuja identidade era localmente definida: costureiras da cooperativa, trabalhadoras da creche, membros da associação do bairro e suas esposas, frequentadores do projeto para jovens, filhos dos membros da associação do bairro, "manos" dos times de futebol locais. Dessa forma, trata-se de um trabalho cuja amostra foi coletada de acordo com categorias que emergem das práticas sociais dos indivíduos em seus grupos, observados na comunidade, na linha dos estudos da terceira onda preconizados por Eckert (1996).

Respectivamente, "Programa de Estudos sobre o uso da Língua" (http://www.letras.ufrj.br/peul/), no Rio de Janeiro; "Variação Linguística Urbana no Sul do País" (http://www.pucrs.br/fale/pos/varsul), que reúne pesquisadores de universidades dos três estados do sul do Brasil; "Variação Linguística no Estado da Paraíba" (HORA, 2004); e "Amostra Linguística do Interior Paulista", no estado de São Paulo. (GONÇALVES, 2003). 
Ainda que se lembrem os projetos de pesquisa e trabalhos acima, a cidade de São Paulo ainda carece de descrição sociolinguística. Com tal preocupação em foco, o Grupo de Estudos e Pesquisa em Sociolinguística da USP (GESOLUSP) vem executando a coleta de dados recentes da fala paulistana, no projeto "SP2010". ${ }^{2}$ Para propor tal projeto, foram previamente gravadas e transcritas, de 2008 a 2010, mais de cem entrevistas (que compõem o que aqui se chama de "Amostra SP-Piloto"), num exercício de observação sociolinguística da cidade, cujos objetivos principais foram promover o treinamento de jovens pesquisadores e definir rumos e parâmetros para o desenvolvimento do então futuro projeto.

Dessa forma, o presente artigo traz notícias acerca da execução de tal projeto de pesquisa (suas bases teórico-metodológicas, seus objetivos principais, desafios e encaminhamentos futuros), bem como reporta pesquisas que foram e vêm sendo desenvolvidas já com os dados da amostra SP-Piloto. As perguntas que congregam esses trabalhos (tanto de construção de corpora quando de sua análise propriamente) são basicamente as seguintes: (i) Como construir uma amostra representativa da fala de uma cidade tão heterogênea e multicultural? (ii) O que significa falar como um paulistano e quais são as variáveis e variantes que o identificam? (iii) Que diferenças sociolinguísticas convivem na capital?

Embora essas perguntas remetam à definição do paulistano de maneira geral, como ser social e linguístico, a terceira das questões também tem sido abordada em termos mais específicos, da perspectiva de certas identidades urbanas - sobretudo no que concerne a questões de sexo/gênero e de classe social. Nesse sentido, esse artigo é organizado em três grandes partes: inicialmente, trata do Projeto SP2010, a partir do relato de experiências na construção da "Amostra SP-Piloto"; em seguida, traz notícia de trabalhos que colocam a comunidade paulistana no centro das atenções; finalmente, dá lugar a críticas ao empreendimento variacionista e ao seu possível endereçamento no trabalho sociolinguístico com a cidade de São Paulo.

\section{A construção de uma (nova) amostra da fala paulistana}

De 2008 a 2010, o GESOL-USP dedicou-se ao acúmulo de experiência nos procedimentos de coleta e organização de um corpus da fala paulistana. Nesse período, foram coletadas e transcritas mais de cem entrevistas, com informantes paulistanos e não paulistanos, de ambos os sexos e de diferentes orientações sexuais, de 15 a 89 anos, com escolaridade equivalente ao Ensino Fundamental incompleto até o Ensino Superior completo, de estratos socioeconômicos diversos, residentes de 27 subdistritos e 59 bairros distintos, distribuídos por cinco zonas da capital paulista (Central, Norte, Sul, Leste e Oeste). Tendo em vista a reconhecida

“SP2010: construção de uma amostra da fala paulistana" (Processo FAPESP n 2011/09278-6). 
complexidade sociodemográfica da cidade, a gravação dessas entrevistas teve um caráter exploratório e objetivou (i) elaborar e aprimorar um roteiro de entrevistas com paulistanos; (ii) elaborar e aprimorar métodos de abordagens a possíveis informantes; (iii) identificar problemas técnicos que podem ocorrer durante a gravação (p.ex., presença de ruídos externos) e metodológicos (p.ex., como conduzir a entrevista de modo que o falante se sinta à vontade), e elaborar soluções para tais problemas; (iv) elaborar critérios para a transcrição das entrevistas; e (v) identificar as variáveis extralinguísticas mais relevantes para a caracterização da fala paulistana.

Do modo como foi elaborado, o roteiro de entrevistas objetiva, além de obter amostras de fala propriamente, reunir informações sobre o modo/condições de vida e avaliações sociolinguísticas dos informantes a respeito de certas variantes. Ele é dividido em duas partes: a primeira é mais pessoal e busca o envolvimento do falante nos tópicos apresentados (bairro, infância, família, trabalho, lazer), de modo que ele possa produzir tanto narrativas quanto descrições nos tempos passado (p.ex., através da pergunta "Como foi sua infância no bairro?"), presente (p.ex., "Nas horas de lazer, o que você e sua família gostam de fazer?"), e futuro (p.ex.: "Se você ganhasse na megassena, o que você faria?"). Embora se volte primariamente para questões que envolvam o informante, essa parte também inclui perguntas a respeito de temas mais gerais, que possibilitam a narrativa em terceira pessoa (p.ex., "Como é a vida em família hoje em São Paulo?"). A segunda parte trata de temas mais "objetivos" sobre a cidade (problemas e possíveis soluções para eles, caracterização da cidade e de seus habitantes) e busca uma fala cujo estilo - no sentido de Labov (2001b) - seja potencialmente mais distanciado e dissertativo/argumentativo. Essa parte também contém a leitura de uma lista de palavras, de uma notícia de jornal e de um texto com características da oralidade, na qual se espera maior grau de monitoramento da fala, em diferentes graus (LABOV, 2001b, 2006); ela se encerra com questões sobre as avaliações dos falantes a respeito de três variantes de variáveis sociolinguísticas específicas: a pronúncia ditongada de /e/ nasal (em palavras como "entendendo"), a ausência de concordância nominal (p.ex. "dois pastel") e a pronúncia retroflexa de /r/ em coda silábica (em palavras como "porta"). Embora o roteiro se divida em dois momentos e diferentes subtópicos, ele permite uma transição bastante natural entre assuntos, com duração total média de 60 a 70 minutos, equilibradamente distribuídos entre as duas partes.

Também de acordo com a experiência prévia, constatou-se que a projeção de uma amostra verdadeiramente aleatória pode inviabilizar a realização da coleta. Os habitantes da cidade, de modo geral, mostraram bastante resistência a participar das gravações quando contatados por meios institucionais (através da USP e por associações de bairro), sem a intermediação de um conhecido em comum. Ainda 
que algumas pessoas assim abordadas tenham aceitado participar das gravações, essas acabaram muitas vezes sendo mais curtas (de 20 a 40 minutos), uma vez que era visível o desconforto dos falantes em fornecer certas informações ou externar suas opiniões acerca dos temas arrolados. Por outro lado, a intermediação de um conhecido em comum se mostrou bastante produtiva; não só a maioria dos falantes que foram contatados desse modo se sentiu mais à vontade para receber os documentadores em suas residências (o que permite maiores observações que podem ser registradas no diário de campo), como também se revelaram bastante solícitos durante as entrevistas e na indicação de novos informantes.

Desse modo, a amostra é semialeatória, já que os informantes são selecionados e contatados a partir de uma adaptação do método "amigo do amigo" (MILROY, 2004) (ver Figura 1): os membros do GESOL-USP buscam, a partir de suas redes sociais (A), a indicação de paulistanos (B) que potencialmente se enquadram num dos 12 perfis elencados no Quadro 1, observando o critério de que a relação entre documentador e informante não deve ser próxima. A partir desses novos contatos, os documentadores pedem a indicação de novos informantes (pontos $\mathrm{C}$ e D) pelas pessoas já gravadas, a fim de ter acesso a um maior número de paulistanos, de perfis variados. Para garantir que um grupo de informantes não se concentre em uma mesma rede social, a nova pessoa indicada (C ou D) não deve ser conhecida da pessoa que indicou o informante atual (A). No exemplo da Figura 1, como C conhece A, C não poderá ser gravado; por outro lado, como D não conhece $\mathrm{A}, \mathrm{D}$ pode ser um novo informante.

\section{Figura 1 - Seleção de informantes por método semialeatório.}

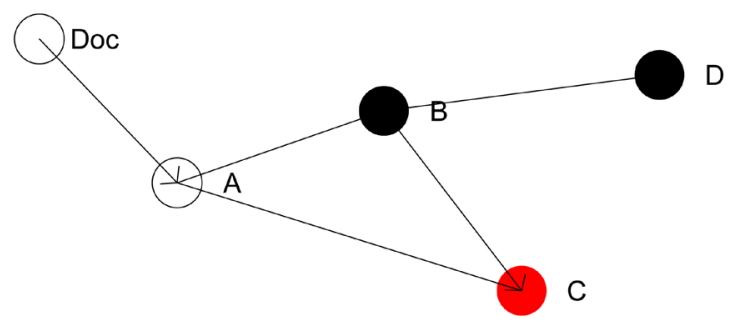

Fonte: Elaboração própria. 
Embora se trate de um método semialeatório de amostragem, a partir dele é possivel atingir um grande número de falantes de diferentes perfis (como se vê pela abrangência geográfica e sociodemográfica da amostra piloto), bem como obter amostras caracterizadas por maior naturalidade de fala. Os critérios de transcrição dessas gravações também passaram por diversas versões. A fim de permitir fácil manipulação em programas como o R (HORNIK, 2011) (para a extração automática de dados, por exemplo), estabeleceu-se que as transcrições seriam feitas em formato .txt (UTF-8), sem formatação especial como negritos, itálicos, TAB, colunas e tabelas, tampouco marcas gráficas para indicar alongamento, apagamento de segmentos ou hesitações. ${ }^{3}$ De acordo com a experiência piloto, quanto maior o número de critérios, mais demorada se torna a transcrição e menos padronizados os produtos finais.

A partir da análise qualitativa das gravações da amostra piloto e com base na literatura sociolinguística (CHAMBERS, 1995; CHAMBERS; TRUDGILL; SCHILLING-ESTES, 2004; LABOV, 1972, 1994, 2001a, 2006; RODRIGUES, 1987; TAGLIAMONTE, 2006), considera-se que são seis os parâmetros mais relevantes para a constituição sociolinguística da comunidade paulistana: Sexo/Gênero, Faixa Etária, Escolaridade, Classe Social, Região da Cidade e Geração da Família na cidade. A construção de uma amostra que contemplasse todas essas variáveis seria, contudo, inexequível a curto prazo; por isso, considerou-se, numa primeira fase, que a amostragem da fala paulistana poderia ser satisfatoriamente executada com base nas três primeiras, do modo como resume o Quadro 1 abaixo. Quanto às demais, elas não definem o tamanho da amostra, mas fazem parte dela qualitativamente.

\section{Quadro 1 - Grupos de fatores definidores da amostra SP2010 e perfis sociolinguísticos dos informantes.}

\begin{tabular}{|c|c|c|c|c|}
\hline $\begin{array}{c}\text { Sexo/Gênero } \\
\text { (F/M) }\end{array}$ & $\begin{array}{c}\text { Faixa Etária } \\
(1 / 2 / 3)\end{array}$ & $\begin{array}{c}\text { Escolaridade } \\
(\mathrm{C} / \mathrm{S})\end{array}$ & $\begin{array}{r}F \\
\text { sociol }\end{array}$ & $\begin{array}{l}\text { fil } \\
\text { uístico }\end{array}$ \\
\hline \multirow{6}{*}{ Feminino } & \multirow{2}{*}{ 20-34 anos } & Até Ens. Médio & 1. & F1C \\
\hline & & Ens. Superior & 2 . & F1S \\
\hline & \multirow{2}{*}{$35-59$ anos } & Até Ens. Médio & 3. & F2C \\
\hline & & Ens. Superior & 4. & F2S \\
\hline & \multirow{2}{*}{$60+$ anos } & Até Ens. Médio & 5. & F3C \\
\hline & & Ens. Superior & 6. & F3S \\
\hline \multirow{6}{*}{ Masculino } & \multirow{2}{*}{ 20-34 anos } & Até Ens. Médio & 7 . & M1C \\
\hline & & Ens. Superior & 8. & M1S \\
\hline & \multirow{2}{*}{ 35-59 anos } & Até Ens. Médio & 9 . & M2C \\
\hline & & Ens. Superior & 10. & M2S \\
\hline & \multirow{2}{*}{$60+$ anos } & Até Ens. Médio & 11. & M3C \\
\hline & & Ens. Superior & 12 . & M3S \\
\hline & perfis $\times 5 \mathrm{i}$ & $\mathrm{es}=60$ gravações & & \\
\hline
\end{tabular}

Fonte: Elaboração própria.

Aplicam-se, contudo, reticências para marcação de pausas e os sinais de exclamação e interrogação para indicar a entonação de certas sentenças. 


\section{Sexo/gênero}

A menos que os propósitos de uma certa pesquisa variacionista fossem especificamente direcionados a uma comunidade de práticas constituída por indivíduos de apenas um dos dois sexos, não faria sentido que uma amostra não incluísse sujeitos-informantes de ambos. Neste sentido, tal grupo de fatores sociais não carece de maiores justificativas, enquanto categoria organizadora de uma amostra de fala. Entretanto, duas esferas de discussão merecem não apenas ser lembradas, como também merecem atenção no desenvolvimento deste projeto: uma delas diz respeito às expectativas de resultados de análises variacionistas, no que concerne ao sexo/gênero dos informantes; a outra se refere à necessidade de descrever as diferenças dos papéis sociais de homens e mulheres no caso específico da comunidade cuja fala se quer amostrar. Muitos são os trabalhos que se dedicam a fazer um quadro sinótico dos resultados das pesquisas sociolinguísticas que incluíram a variável sexo/gênero em suas análises - desde aquele que se considera o primeiro manual desenvolvido para a área (CHAMBERS, 1995), até manuais mais recentes (CHAMBERS; TRUDGILL; SCHILLINGESTES, 2004; HOLMES; MEYERHOFF, 2005). Em todos eles, invariavelmente se mencionam, quando não se discutem extensivamente: (i) o fato de que, nas sociedades ocidentais especialmente, a frequência de variantes prestigiadas ou positivamente avaliadas numa dada comunidade é maior na fala das mulheres, relativamente à dos homens; (ii) em mudanças linguísticas "de baixo", as mulheres podem se revelar mais conservadoras; (iii) em mudanças "de cima", as mulheres tendem a se revelar mais inovadoras (GUY, 1990; LABOV, 2001a).

Ora, num projeto que se propõe a construir uma amostra recente da fala de uma grande comunidade urbana tal como São Paulo, é mister oferecer uma descrição acerca dos papéis sociais (gênero) correlacionados às diferenças entre os dois sexos. Por um lado, é necessário admitir a validade de uma crítica insistente, por parte de sociolinguistas que preconizam, em suas pesquisas, uma observação etnográfica e maior atenção às práticas sociais: aquela que aponta para o fato de que, embora se fale em termos de diferenças gênero, na verdade se trabalha - por vezes, de maneira essencialista - com a diferença de sexo (ECKERT; MCCONNELL-GINET, 1992). Por outro lado, papéis sociais estão em constante processo de construção e reconstrução e, no Brasil, São Paulo talvez seja uma das cidades em que estilos de vida, hábitos urbanos e práticas sociais em geral mudem mais rapidamente. Dessa forma, é importante verificar, no caso de uma comunidade de fala ainda não suficientemente estudada como a cidade de São Paulo, se as tendências sociolinguísticas descritas em inúmeros estudos observam-se também aqui. Além disso, o desenvolvimento deste projeto também traz subsídios para outras pesquisas que se interessam mais especificamente pela variável sexo/gênero, no formato de um elenco de informações sobre as 
práticas sociais dos indivíduos, homens e mulheres, que são selecionados para a construção desta amostra - ainda que de maneira relativamente distanciada, como é o caso da entrevista sociolinguística.

\section{Faixa etária}

Assim como sexo/gênero, o grupo de fatores faixa etária está entre aqueles mais analisados em estudos sociolinguísticos. Sua ampla utilização na estratificação de amostras de fala se baseia no conceito de mudança em tempo aparente e na hipótese de que é possível detectar mudanças linguísticas em progresso através da comparação da fala de pessoas de diferentes idades pertencentes à mesma comunidade (LABOV, 2001a). Além disso, assim como sexo/gênero, a faixa etária frequentemente se revela correlacionada a variáveis linguísticas cujas variantes se diferenciam em graus de prestígio numa comunidade. Desse modo, a inclusão desse grupo de fatores permite investigar, nos trabalhos que se desenvolvem com base nesta amostra, se certos fenômenos linguísticos encontram-se em variação estável ou em mudança no português paulistano, além de avaliar diferentes graus de prestígio ou de estigma de certas variantes.

Cabem aqui, entretanto, alguns esclarecimentos quanto à segmentação etária definida. Esta amostra inclui falantes (i) de 20 a 34 anos, (ii) de 35 a 59 anos, e (iii) com 60 anos ou mais. Trata-se, portanto, apenas de falantes em idade adulta, uma vez que a inclusão de crianças e de adolescentes poderia aumentar significativamente o número mínimo de entrevistas a serem gravadas, inviabilizando a obtenção de 5 informantes por perfil. Por outro lado, a divisão em pelo menos três faixas faz-se necessária a fim de diferenciar variantes em retração ou difusão (em que normalmente se verifica um padrão de curva ascendente ou descendente) e variantes de variáveis estáveis (em que normalmente se observa um padrão de curva em "U").

A presente classificação toma por base, principalmente, a posição relativa das faixas etárias no mercado de trabalho, mas também leva em conta modos/ estilos de vida de cada grupo, caracterizados aqui in abstracto. O grupo de falantes mais novos, aqueles entre 20 e 34 anos de idade, engloba jovens adultos que, em geral, encontram-se relativamente menos estabilizados do que pessoas das outras duas faixas etárias: na cidade de São Paulo, não é raro encontrar pessoas com até 34 anos de idade que não tenham se casado, que não têm casa própria, que estão fazendo faculdade ou cursos profissionalizantes ou que, de modo mais amplo, levam um estilo de vida mais semelhante ao de pessoas com vinte e poucos anos. O grupo de falantes entre 35 e 59 anos, por sua vez, pretende abarcar pessoas mais plenamente inseridas no mercado de trabalho e relativamente mais estáveis (ou que buscam mais seriamente certa estabilidade). 
Por fim, o grupo de falantes com mais de 60 anos se refere de modo amplo a pessoas aposentadas ou próximas da aposentadoria.

Essa caracterização, é claro, não é uma regra para todos os falantes certamente existem pessoas com 23 anos que são casadas e que têm emprego estável, assim como há pessoas com 47 anos que são solteiras e que não têm estabilidade profissional -, mas parece adequada às fases da vida na metrópole. Ao mesmo tempo, não se pretende dar a entender que falantes contatados que não se encaixam na descrição acima não são considerados na amostra; a proposta de 5 informantes por perfil objetiva justamente permitir relativizar tais variações entre indivíduos.

Como se trata de um contínuo, o agrupamento em determinadas faixas etárias não deixa de ser arbitrário até certo ponto, e pode, em princípio, ser reorganizado de outras maneiras. Na construção da amostra SP2010, a ficha de cada informante indica a sua idade (e não apenas a sua faixa etária), de modo que diferentes pesquisas terão a possibilidade de reagrupar os falantes, se assim considerar necessário, ou tratar esse grupo de fatores como variável contínua.

\section{Escolaridade}

A escolaridade dos falantes (dividida em dois níveis: até Ensino Médio; Curso Superior completo ou incompleto) compõe a terceira variável extralinguística que estratifica a amostra da fala paulistana em construção no Projeto SP2010. Assim como sexo/gênero e faixa etária, trata-se de uma variável bastante analisada nos estudos sociolinguísticos brasileiros e serve, em princípio, como parâmetro para analisar o impacto da instrução formal no emprego de formas linguísticas. A expectativa é que falantes com graus mais elevados de instrução apresentem maior tendência de emprego de formas consideradas padrão ou de prestígio na comunidade e evitem as formas consideradas não padrão ou estigmatizadas.

Ao mesmo tempo, tal variável tem sido tradicionalmente empregada como modo indireto de avaliar a classe social do falante (RODRIGUES, 2009), uma vez que o grau de instrução se correlaciona com atividades profissionais possíveis e respectivos salários médios dos indivíduos. No entanto, se a realidade socioeconômica brasileira na década de 1970, em que se começaram a coletar amostras de língua falada no país, permitia uma equação relativamente pacífica entre classe social e escolaridade do falante, por outro lado, mudanças nas políticas públicas de educação nas últimas décadas, como a Progressão Continuada (no estado de São Paulo) e a ampliação do acesso aos cursos universitários através do ProUni (no âmbito federal), permitem um sério questionamento dessa equivalência na década de 2010, sobretudo na cidade de São Paulo. 
A divisão em apenas dois níveis de escolaridade é decorrência dessas mudanças. A partir da experiência piloto, constatou-se que é cada vez mais raro encontrar paulistanos nativos que não tenham pelo menos ingressado no Ensino Médio (embora tal realidade ainda seja relativamente mais frequente entre migrantes); 4 uma estratificação mais complexa, além de aumentar o número mínimo de informantes, poderia conduzir à inviabilidade de preencher certas células (por exemplo, falantes da primeira faixa etária que não tenham concluído o Ensino Fundamental). Sugere-se aqui que escolaridade deva ser tratada como um fator de composição da classe social do falante, mas não como sua substituta. Desse modo, a inclusão dessa variável no presente projeto tem o objetivo de instrumentalizá-la posteriormente no desenvolvimento de critérios para o estudo da variável classe social.

\section{Classe social, região da cidade e geração da família na cidade}

Essas variáveis, conforme já se apontou, não definem o tamanho da amostra. Entretanto, parece evidente que as três variáveis anteriormente discutidas não abarcam, por si sós, características que potencialmente distinguem São Paulo de outras comunidades linguísticas, dadas as suas especificidades históricas, culturais e sociodemográficas. Nesse sentido, vale também discutir a importância e os modos como essas três variáveis adicionais são observadas na execução do projeto, mantendo-se em perspectiva a dupla finalidade de (i) aumentar a representatividade da amostra; e (ii) aprofundar reflexões sobre a possibilidade de operacionalizar essas variáveis em amostras futuras.

Classe social parece apresentar-se como um fator relevante para a diferenciação sociolinguística na cidade de São Paulo. Nas gravações da experiência piloto, em resposta à pergunta "Dentro da cidade de São Paulo, você consegue identificar se a pessoa é de alguma região ou bairro específico da cidade?", frequentemente se obtiveram respostas tangentes, que mencionam a classe socioeconômica dos falantes, a despeito de que a pergunta houvesse sido formulada com base em um parâmetro geográfico. Adicionalmente, em um experimento controlado de percepções (MENDES; OUSHIRO, 2011a, 2011b) com aplicação da técnica matched-guise (CAMPBELL-KIBLER, 2009), constata-se que classe social é uma das variáveis extralinguísticas mais significativamente correlacionadas à pronúncia variável de /-r/ em coda silábica na cidade de São Paulo: os ouvintes paulistanos atribuíram, em média, níveis de classe social mais baixos quando ouviram estímulos em que falantes empregavam a variante retroflexa do que quando ouviram a variante tepe.

De fato, de acordo com os Resultados Gerais do Censo Demográfico (IBGE, 2010, p.84 ss.), o percentual de pessoas em idade escolar (7-14 anos e 15-17 anos) que não frequentam escola diminuiu de modo geral em todo o país nos últimos 10 anos, de 22,6\% para 16,7\%, sendo a Região Sudeste aquela que apresenta menor taxa de evasão escolar (de 20,1\% para 15,0\%). Tal fato se percebe facilmente no trabalho de campo. 
No entanto, classe social é uma variável difícil de abordar. Em primeiro lugar, porque seria necessário estabelecer critérios sociolinguísticos - e não estritamente econômicos - que permitissem o estudo da comunidade paulistana. Tais critérios possivelmente devem abarcar, além da renda familiar e do já mencionado nível de escolaridade, o tipo e o local de residência, a ocupação, o acesso a bens culturais etc. (ASH, 2004). ${ }^{5}$ Paralelamente à construção da amostra SP2010, Faria (2012) vem trabalhando na definição de critérios suficientemente objetivos para a proposta de uma classificação socioeconômica dos falantes paulistanos. ${ }^{6}$ A observação de diferenciações socioeconômicas na construção da Amostra SP2010 se baseia em perguntas formuladas no roteiro da entrevista sociolinguística com todos os informantes (p.ex., sobre o nível de escolaridade, ocupação, área de residência do informante, meios de locomoção utilizados, formas de lazer, lugares a que já viajou etc.), e no preenchimento de um questionário específico (questões no formato de múltipla-escolha sobre, p.ex., a renda individual e familiar, tipo e posse de habitação etc.). Assim, no Projeto SP2010, a classe social dos falantes é determinada a posteriori, e um determinado estudo poderá se valer de tais diferenciações, de acordo com seus objetivos.

\section{Figura 2 - Divisão da cidade de São Paulo em Centro Velho, Centro Expandido e Periferia.}

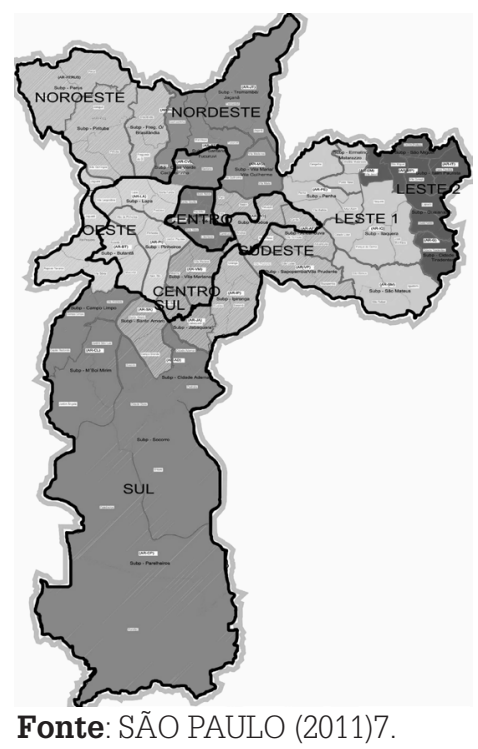

\footnotetext{
Os critérios do IBGE para a classificação socioeconômica dos falantes baseiam-se exclusivamente na renda dos habitantes, o que não parece dar conta dos diferentes níveis de status social na cidade de São Paulo e de suas correlações com usos linguísticos.

6 Esse trabalho é descrito com mais detalhes na terceira parte deste artigo.

7 A divisão da cidade em três áreas foi feita pelo GESOL-USP, de acordo com os critérios descritos.
} 
De modo semelhante, o local de habitação do falante em diferentes regiões da cidade tem potencial para revelar diferenciações sociolinguísticas. Embora a cidade seja dividida administrativamente em 31 subprefeituras, distribuídas em nove zonas, dois tipos de divisão geográfica surgiram mais frequentemente no discurso de paulistanos nas entrevistas piloto: (i) a divisão entre as zonas Central, Norte, Sul, Leste e Oeste; e (ii) uma divisão entre Centro Velho, Centro Expandido e Periferia (ver Figura 2, acima). A divisão em cinco zonas não apresenta maiores dificuldades, visto que os seus limites são bastante claros. Já a proposta de limites para a divisão em três regiões - Centro Velho, Centro Expandido, Periferia Próxima -, tem base na história de ocupação dos bairros e no grau de desenvolvimento urbano em termos de verticalização e serviços (OUSHIRO, 2011b). Na primeira região, incluem-se bairros como Bela Vista, Consolação, Bom Retiro, Brás, Liberdade, que representam a São Paulo "mais antiga", em que se encontram mais facilmente informantes cujas famílias estão enraizadas na cidade há mais tempo (há duas ou mais gerações); esses falantes podem apresentar uma tendência maior de empregar formas linguísticas consideradas prototipicamente paulistanas. No Centro Expandido, incluem-se bairros como Pinheiros, Santana, Vila Mariana, Moema, Tatuapé. Assim como o Centro Velho, tais bairros já são amplamente verticalizados e possuem uma infraestrutura relativamente bem desenvolvida de serviços (ônibus, metrô, hospitais, todos os tipos de comércio). No entanto, diferentemente do Centro Velho, aí se localizam os imóveis mais caros da cidade e que relativamente mais se valorizam. Na região mais periférica, incluem-se bairros como Sapopemba, Pirituba, Jabaquara, Freguesia do Ó, Vila Matilde, que são historicamente mais recentes, assim como seu processo de verticalização; neles, ainda é possível ver crianças brincando na rua e vizinhos conversando ao portão de suas residências, fatos de sociabilidade que potencialmente têm consequências para o repertório sociolinguístico desses habitantes. A Figura 2 representa essa divisão da cidade em três regiões aproximadamente concêntricas em relação ao seu centro político e geográfico. Na coleta de entrevistas da presente amostra, o número de informantes por perfil é equilibrado a partir dos dois tipos de categorização geográfica: um informante por zona e um ou dois informantes por região. Esse critério visa a cumprir a tarefa de obter uma amostra representativa e minimamente abrangente da cidade.

Finalmente, quanto à geração da família na cidade, a proposta do Projeto SP2010 amostra é incluir apenas informantes paulistanos (ainda que seus pais possam não sê-lo), e que não se considerem migrantes e imigrantes. Embora estes últimos certamente tenham um papel importante na constituição sociolinguística da cidade, a sua inclusão pressuporia responder certas questões que parecem colocar-se em outro momento da pesquisa, posterior àquele em que correntemente se encontra, tais como: (i) no caso dos migrantes, quantas e quais regiões de origem deveriam ser consideradas? (ii) no casos dos imigrantes, incluir-se-iam "apenas" 
aqueles mais tradicionalmente considerados (os japoneses, os italianos, os árabes), ou também grupos de imigração mais recente (os bolivianos, os coreanos)? (iii) no caso de ambos, quais gerações seria importante incluir na amostra? Os mesmos critérios poderiam ser aplicados aos diferentes grupos?

Na amostra em construção, os documentadores devem obter informações acerca de que geração de paulistanos o falante é representante - se os pais (um deles ou ambos) são paulistanos ou não, se um ou mais avós são paulistanos - e da(s) origem(ns) da primeira geração da família que veio para São Paulo (de que outra cidade, estado ou país). Tais informações fazem parte da Ficha do Informante e da Gravação, de modo que, ainda que não constituam um dos parâmetros de estratificação desta amostra, poderão ser objeto de análises linguísticas (para investigar, por exemplo, se a fala de paulistanos exibe padrões quanto ao grau de enraizamento da família na cidade).

O Projeto SP2010 se constitui, então, como um novo movimento na amostragem da fala paulistana, com objetivos variacionistas bem delimitados e definidos sobretudo com base na noção laboviana de comunidade de fala. A partir das experiências acumuladas na construção da Amostra SP-Piloto, seu desenvolvimento poderá levar ulteriormente a propostas de construção de amostras que se definam diferentemente e que complementem a que se desenvolve no presente, aproximando-se progressivamente de um quadro sociolinguístico mais rico da capital paulista; o trabalho de observação da comunidade que tem continuidade ao longo da execução do projeto fornecerá subsídios para o amadurecimento das questões levantadas. Ao final de 2013, a amostra construída pelo Projeto SP2010 deverá ser disponibilizada em página própria na Internet, de modo que outros centros de pesquisa possam utilizá-la.

\section{Estudando o português falado na cidade de São Paulo}

Conforme já se indicou anteriormente, alguns trabalhos foram e vêm sendo desenvolvidos já com os dados da Amostra SP-Piloto. Entre os trabalhos já finalizados, encontram-se as dissertações de mestrado de Oushiro (2011a) e Nascimento (2011).

A partir de 53 entrevistas (além de outras amostras de língua escrita), Oushiro (2011a) analisa a variação entre quatro estruturas de Interrogativas-Q no português paulistano contemporâneo: (i) interrogativas-qu ("Onde você mora?"); (ii) interrogativas qu-que ("Onde que você mora?"); (iii) interrogativas é-que ("Onde é que você mora?"); e (iv) interrogativas qu-in-situ ("Você mora onde?"). Um dos aspectos mais interessantes desse trabalho é a discussão da equivalência semântica entre as formas interrogativas, estabelecida com base no conceito de 
pressuposição do falante (STALNAKER, 2002) - num exercício de superação do debate Lavandera-Labov (LAVANDERA, 1978; LABOV, 1978). Além disso, Oushiro (2011a) utiliza o conceito de competência comunicativa (HYMES, 1991) como critério para definir os envelopes de variação com que trabalha: diferentes estruturas são consideradas variantes se forem possíveis, factíveis, adequadas e efetivamente empregadas nos mesmos contextos. Com base nesses conceitos, definem-se dois envelopes de variação - e, portanto, duas variáveis: uma envolve a alternância na posição do constituinte interrogativo (in situ ou não), e outra que encerra as três estruturas com constituinte interrogativo pré-verbal (-qu, qu-que e é-que ).

Em resumo, os resultados das análises quantitativas mostram que interrogativas qu-in situ são favorecidas principalmente por fatores morfossintáticos e discursivo-pragmáticos. ${ }^{8}$ Entretanto, da perspectiva social, um dos resultados mais interessantes dessa pesquisa com dados paulistanos é aquele que revela um diferenciação entre homens e mulheres: eles tendem a empregar diferentes estruturas sintáticas em relação a uma mesma estratégia discursiva - para as mulheres, a estrutura de interrogativas qu-in-situ parece estar mais associada a perguntas retóricas do que para os homens, que a desfavorecem fortemente no mesmo contexto. Ao cruzar fatores discursivopragmáticos com a variável sexo/gênero, Oushiro (2011a) revela evidências muito favoráveis à hipótese de Cheshire (2005) a respeito do encaixamento social indireto da variação sintática (diferentemente do que em geral se observa quando se trata de variáveis fonético-fonológicas). Já no que toca ao emprego de interrogativas qu-que, a autora aponta para evidências de mudança linguística em progresso, uma vez que sua análise em tempo aparente revela o favorecimento da estrutura pelos falantes mais jovens. Neste caso, demonstra que a variação é influenciada principalmente por fatores sintáticos e prosódicos.

Nascimento (2011), por sua vez, trata da variação no uso do pronome de segunda pessoa, cujas formas alternativas empregadas pelos paulistanos são "você(s)" e "cê(s)". A partir de 36 entrevistas com paulistanos, gravadas pelo GESOL-USP, e de 18 entrevistas do NURC-SP, a autora analisou essa variável sincrônica e diacronicamente. Seus resultados mostram um equilíbrio na distribuição das duas variantes nos seus usos por paulistanos. Embora se evidencie mudança em progresso pelos dados do NURC-SP (coletados na década de 1970), a análise com os dados dos anos 2000 revela um caso de variação estável na comunidade de fala.

Com a amostra recente, Nascimento (2011) mostra que a variante inovadora "cê" tende a ocorrer mais na fala dos mais jovens e das mulheres acima de 50 anos de idade, bem como nas interações entre pessoas que se conhecem mais (comparativamente

8 Para uma discussão pormenorizada, mas mais breve e objetiva do que numa dissertação de mestrado, veja-se também Oushiro (2011c). 
a indivíduos que são completos desconhecidos entre si). Por outro lado, a forma "cê" tende a ser evitada entre os mais escolarizados. Linguisticamente, o emprego das variantes revela-se correlacionado a fatores semânticos e discursivos, sobretudo à referência do pronome. No que concerne a questões de gramaticalização, os resultados a que chegou a pesquisadora corroboram a hipótese de cliticização da variante reduzida, mas fornecem um contra-argumento à correlação direta entre "erosão fonética" e "abstratização semântica".

Além dessas pesquisas já finalizadas, as entrevistas coletadas pelo GESOLUSP têm nutrido outras várias, em andamento. Rocha (2012a, 2012b) vem estudando, no nível de mestrado, a estruturação variável de sentenças negativas, com o emprego do advérbio de negação apenas antes do predicado verbal ou com seu emprego antes e depois do verbo, como em "Não vou mais fazer faculdade" (NEG1) e "Não vou mais fazer faculdade não" (NEG2). A partir de 48 entrevistas, Rocha (2012a, 2012b) constata três fatos interessantes: (i) a estrutura NEG2 parece bastante infrequente entre paulistanos (menos de $10 \%$ do total de dados); (ii) a variação não parece possível quando se trata de negação de proposição que veicula informação completamente nova no discurso (parece variável quando a informação da proposição que está sendo negada é ativada, direta ou indiretamente, no discurso precedente); (iii) a estrutura NEG2 parece mais frequente entre paulistanos cujos pais são oriundos do nordeste brasileiro. Some-se a esses o fato observado de que uma terceira estruturação possível, em que o advérbio de negação aparece apenas após o verbo - como em "Vou mais fazer faculdade não" (NEG3) - parece muitíssimo infrequente na fala paulistana.

Esses são resultados preliminares que ainda carecem de análises ulteriores, mas sua discussão apresenta-se promissora, não apenas no que diz respeito à descrição do fenômeno na fala paulistana, mas também no que concerne à definição do envelope de variação - tarefa sempre complexa, mas das mais instigantes para o campo da sociolinguística em que se dedica a variáveis que estão "além" do nível fonético-fonológico.

Em outra pesquisa em nível de mestrado, Silva (2011) focaliza a variável concordância nominal (tanto no interior de sintagmas nominais, como em casos de predicativos), a partir de duas amostras; uma delas é constituída de 36 informantes paulistanos de facto (nascidos e criados em São Paulo, dentre os já gravados pelo GESOL-USP) e a outra é constituída de 36 alagoanos que se mudaram para a capital paulista (há mais de dez, menos de dez e menos de dois anos). Sua proposta, além de verificar os fatores sociais e linguísticos que regulam esse caso de variação nessa comunidade, é também verificar até que ponto esses subgrupos se assemelham e se dessemelham. Uma das principais contribuições potenciais desse trabalho, parece claro, é a inclusão da figura do migrante num estudo variacionista em São Paulo, de maneira controlada e rigorosa. Esse trabalho 
tem preocupações semelhantes às da análise de Mendes (2011a, 2011b) que, com base em uma primeira amostra de entrevistas com falantes paraibanos enraizados em São Paulo, discute as tendências de acomodação de fala de um dos muitos grupos de migrantes residentes na cidade.

Um outro trabalho em que se comparam amostras é a pesquisa de doutorado de Vieira (2012). Neste caso, trata-se do estudo de duas variáveis (a estrutura de orações relativas - padrão, copiadora e cortadora - e o preenchimento variável de preposição em sintagmas preposicionados) com dados da fala paulistana e campo-grandense. Os dados da capital do Mato Grosso do Sul estão sendo coletados de acordo com os perfis definidos pelo Projeto SP2010 (e a partir da experiência com a constituição da Amostra SP-Piloto), com as devidas adaptações que se julgaram necessárias (no roteiro de entrevista, por exemplo) no sentido de coletar informações etnográficas específicas sobre os informantes naturais de Campo Grande. Para as estratégias de relativização, a hipótese de partida de Vieira (2012) é a de que, na norma culta, a variação entre as orações relativas está centrada nas variantes padrão e cortadora, enquanto que o emprego da variante copiadora, de caráter estigmatizado, estaria correlacionado a fatores discursivopragmáticos. Para o apagamento de preposições, por outro lado, a pesquisadora questiona, sobretudo, sua produtividade entre falantes cultos.

A correlação entre variáveis na definição de uma comunidade de fala, de maneira geral, não é frequentemente observada, na divulgação da pesquisa sociolinguística brasileira. A partir dessa constatação, e interessada em ir mais longe no estudo da comunidade de fala paulistana, a pesquisa de doutorado de Oushiro (2011b) propõe investigar a produção e a percepção de variantes linguísticas na cidade de São Paulo que parecem estar correlacionadas a diferentes identidades urbanas: a realização de /r/ em coda silábica como tepe ou retroflexo; a pronúncia de /e/ nasal como monotongo ou ditongo; a presença ou ausência de morfema de plural em sintagmas nominais; e a presença ou ausência de morfema de plural em sintagmas verbais. Seu objetivo central é examinar a distribuição linguística e social das variantes, a fim de verificar (i) que identidades urbanas estão associadas ao seu emprego; (ii) como funcionam os mecanismos de adesão ou resistência a certas normas linguísticas em relação a diferentes grupos sociais; e (iii) se a cidade de São Paulo pode ser considerada uma única comunidade de fala. Para a investigação de produção linguística, Oushiro analisa as mais de cem entrevistas sociolinguísticas coletadas em 2008-2010 pelo GESOL-USP; para a análise de percepção linguística, aplica a técnica matched-guise em testes com controle de variantes (MENDES; OUSHIRO, 2011a 2011b). Além de contribuir para a descrição e a análise de fatos linguísticos no português paulistano, o exame dessas quatro variáveis sociolinguísticas vai permitir a comparação de padrões de covariação entre variáveis dependentes, bem como deverá levar a uma melhor 
compreensão dos processos que conduzem à criação de identidades sociais através de usos linguísticos.

Finalmente, mas não menos importante, deve ser mencionado o trabalho de iniciação científica de Ciancio (2012), que se propõe a construir uma subamostra da fala paulistana especificamente dos moradores do bairro do Itaim Bibi, com dois objetivos centrais: (i) estudar possibilidades de ampliação e continuação do Projeto SP2010; e (ii) encaminhar o estudo da fala de classes mais altas em São Paulo. O interesse nesse bairro se justifica na medida em que, na última década, vem se valorizando extremamente, o que pode ser exemplificado pela alta nos preços dos imóveis, assim como pela multiplicação de empreendimentos prestigiosos, tais como restaurantes, bares, hotéis, cinemas etc. Considere-se ainda que o surgimento do Itaim Bibi como um bairro popular, ${ }^{9}$ por volta dos anos 1920-1930, contrasta com essa valorização dos últimos dez anos, de modo que é possível encontrar e dividir seus moradores da seguinte maneira: (i) paulistanos que moram no Itaim Bibi há um longo tempo (mais de quinze anos) e que, portanto, não escolheram o bairro em virtude de seu desenvolvimento; (ii) pessoas que moram no Itaim Bibi há menos de quinze anos, que acompanharam sua expansão e contribuíram com ela; e (iii) recém-chegados (residentes no bairro há menos de dois anos) que possivelmente buscam os benefícios dessa expansão. Essa variável, de fato, define-se como "grau de enraizamento dos habitantes no bairro", e seu estudo deverá trazer contribuições interessantes para futuros estudos sociolinguísticos na cidade de São Paulo.

\section{Identidades urbanas}

A construção de amostras de fala em comunidades urbanas, e o subsequente estudo de variáveis sociolinguísticas a partir dos dados coletados, em geral têm, na sua base epistemológica, a premissa de que o uso de formas alternativas é linguisticamente indiferente, mas socialmente significativo (CHAMBERS, 2004). Apesar do inegável esforço que caracteriza o empreendimento variacionista afinal de contas, não é possível descrever e explicar os usos linguísticos numa comunidade de fala a partir de poucos dados ou de dados intuídos - é válida a crítica, muitas vezes advinda de vertentes de estudos sociolinguísticos que se pautam por questões de natureza mais etnográfica e antropológica, de que os estudos variacionistas pecam por lidar com categorias pré-estabelecidas. Em outras palavras, muitas vezes os estudos variacionistas são criticados em virtude do fato de que a descrição e explicação das estruturas linguísticas em uso se deem em detrimento de real observação da realidade social e de categorias "locais", em vez de pretensamente "universais".

9 Ver: SÃO PAULO ([2011]); ITAIM BIBI ([2011]). 
Duranti (2001) esclarece e resume essas críticas em três pontos: (i) não é universalmente aceito, nas ciências sociais, o tratamento de categorias tais como classe social, sexo/gênero, raça e geração enquanto variáveis independentes entre si; (ii) é comum a ausência, nos estudos sociolinguísticos quantitativos, de uma definição de "contexto" como algo que está sempre mudando e que tem na referência a fala um de seus elementos constitutivos; (iii) se a fala é uma realização interacional, não se deveria ter a entrevista sociolinguística como o método mais confiável para acessar falas espontâneas. Todos esses pontos, embora não invalidem as décadas de estudos labovianos ao redor do globo, representam desafios para o futuro do campo.

Com essas questões em mente, o GESOL-USP vem se dedicando também ao trabalho de observar e definir categorias sociais, do modo como elas se constroem localmente no espaço urbano paulistano. Evidentemente, isso vem sendo feito paralelamente a - e não em detrimento de - todas as atividades acima descritas. Colocar-se nessa via intermediária talvez implique incessável atenção à premissa de que a performance linguística e a expressão/construção de uma identidade social estão ligadas por uma via de mão dupla: de um lado, a linguagem porta significados simbólicos e sociais; de outro, os falantes dão-se conta dessa propriedade da linguagem e se valem disso para expressar e para veicular significados sociais.

É o caso, portanto, de observar a variação no estilo de linguagem (no sentido de Eckert (2001)), a fim de se ter acesso às variantes linguísticas que um determinado falante está empregando em determinado momento e situação, bem como às funções sociais específicas que tais variantes desempenham. Antes de tratar especificamente de trabalhos que têm sido desenvolvidos nessa linha, vem ao caso organizar seus pressupostos mais básicos. Primeiramente, é preciso rever como se dá a associação entre uso linguístico e significado social, para depois passar à questão da variação no estilo.

Labov (2006), no seu estudo sobre a estratificação social do inglês falado em Nova Iorque, é considerado um dos pioneiros no demonstrar que variantes linguísticas discretas podem veicular informações sociais que caracterizam o sujeito-falante. Essas variantes podem ser mapeadas numa estratificação social mais ampla, caracterizando o grupo de indivíduos que as empregam. No esforço por desenvolver uma teoria social da linguagem, começou-se a explorar a possibilidade de que as variantes linguísticas não apenas caracterizam a linguagem de um certo grupo social, mas também podem ser usadas por indivíduos que queiram indicar sua afiliação a uma determinada comunidade. O exame desse papel de "índice" que os usos da linguagem podem desempenhar já chegou a ser feito por Trudgill (1974) e Milroy (1980) - em estudos da fala da classe operária de 
Norwich e Belfast, respectivamente -, e por Bell (1999), que estudou a linguagem dos noticiários de rádio em Auckland, Nova Zelândia.

Trudgill (1974), em seu exame da pronúncia variável do -ing em final de palavra, observou que os homens alegavam usar a variante não padrão [In], enquanto que as mulheres preferiam empregar a variante padrão [Ih]. Essa descoberta ilustra o fato de que os falantes de uma língua fazem avaliações acerca dos seus diferentes estilos de fala e que têm consciência delas. Em seu estudo, Trudgill (1974) demonstra que o emprego de uma variante bem como a avaliação de seu emprego, sobretudo no caso dos homens, serviam ao propósito de marcar seu pertencimento a um determinado grupo social, atestando a associação simbólica entre linguagem e comunidade e oferecendo uma das primeiras contribuições para os estudos da linguagem como meio de construção de identidade.

Milroy (1980) introduziu nos estudos sociolinguísticos a noção de redes sociais. Em seu estudo de três comunidades operárias de Belfast, a autora argumenta que as propriedades que caracterizam a rede social de um indivíduo influenciam sua performance linguística. Ela também afirma que as redes sociais mais densas aquelas em que todos os membros se inter-relacionam intensamente e interagem uns com os outros numa diversidade de situações - constituem um mecanismo poderoso de normativização de sua fala. Tal mecanismo acaba desempenhando papel decisivo na homogeneização de crenças e práticas sociais dentro do grupo, o que obviamente inclui as práticas linguísticas. Está implícita nessa noção a consciência, tanto da parte dos indivíduos como da parte da comunidade, das práticas sociais que os definem ou que os caracterizam. A conformidade com o padrão linguístico que define o grupo requer a percepção do que constitui um padrão, além da noção de que a linguagem funciona como "índice" de afiliação social dos indivíduos a seu grupo.

Bell (1999), em seu exame da linguagem dos noticiários de rádio em Auckland, analisou a variação no nível individual como um processo que ele chama "Design da Audiência", a partir do que se reconhece como Teoria da Acomodação (GILES; POWESLAND, 1997). O princípio básico dessa teoria é o de que um falante pode optar entre acomodar-se à fala de seu interlocutor - assemelhando sua performance linguística à dele - ou distanciar-se dela. Essa escolha tem significação social no contexto discursivo e indica solidariedade ou diferenciação social, respectivamente. A acomodação linguística é analisada como uma resposta sob a forma de alternância no estilo de falar, na qual o interlocutor adota práticas linguísticas variáveis com base na linguagem do outro. Bell (1999) generalizou tal noção numa teoria de "alternância de estilo", de modo que a variação observada no nível individual pode ser quantitativamente correlacionada ao interlocutor ou ao tópico da conversa. 
A teoria da acomodação está fundada no "Axioma do Estilo", de acordo com o qual a variação observada na fala do indivíduo mimetiza a variação observada entre dois grupos sociais. Em outras palavras, o estilo de linguagem deriva seu significado social da avaliação que o falante faz das relações entre traços linguísticos e grupos sociais. Apesar de manter a generalização de que as comunidades de fala são caracterizadas por traços linguísticos específicos, e a de que ambos são socialmente avaliados pelo falante, essa teoria é inovadora na medida em que traz a noção de que os próprios falantes podem, individualmente, variar seu estilo de fala a fim de atingir diferentes objetivos sociais. Se os falantes podem adotar traços linguísticos socialmente marcados no intuito de evidenciar sua associação ou dissociação diante de seu interlocutor (unitário ou coletivo), tem-se aí o papel do indivíduo na construção da identidade linguística.

Se, por um lado, essas teorias fornecem um bom modelo para a implementação de uma linguagem socialmente marcada, por outro lado elas deixam a desejar no que diz respeito ao desenvolvimento das diversas avaliações que os fatos linguísticos podem permitir. Entretanto, essa lacuna vem sendo preenchida por trabalhos sobre a interação entre linguagem e ideologias sociais. A teoria da indexação de Ochs (1991) oferece um modelo de análise das relações entre linguagem e identidade, no qual traços linguísticos funcionam como "índices" de ideologias sociais. De acordo com essa autora, a relação entre variantes e identidades é indireta, e, por isso, são raras as variantes linguísticas que funcionam como "índices" de uma única e exclusiva identidade social. Para Ochs, elas funcionam antes como "índices" de atitudes, posicionamentos, atividades, que por sua vez estão associadas a categorias sociais.

Com isso, observa-se o desenvolvimento de uma teoria rigorosa sobre os modos como o significado social e sua avaliação se mapeiam sobre a estrutura linguística. Os indivíduos têm consciência dessa propriedade da linguagem, e manipulam-na para a construção de sua identidade social. Bell (1999) considera que o indivíduo pode alternar seu estilo de fala não apenas como uma "resposta" ao seu interlocutor real, mas também por acomodação a um tópico e/ou interlocutor não presentes no contexto de fala. Ou seja, mais uma vez, o indivíduo num dado contexto de fala faz uso de seu conhecimento da relação entre traços linguísticos e identidade social, adotando marcas para "indexar" sua afiliação a um determinado grupo.

Define-se, dessa forma que pode ser identificada como mais "eckertiana", uma linha de estudos que se ocupa mais detidamente das variantes linguísticas como índices de posicionamentos e afiliações sociais. Evidentemente, essa linha não implica a negação daquela mais laboviana - até porque se constitui a partir dela. No GESOL-USP, os estudos e discussões nessa linha têm-se debruçado principalmente sobre identidades de sexo/gênero e de classe social. 


\section{Sexo/gênero}

Mendes (2007, 2011a) desenvolveu um experimento de percepção e avaliação linguística em que perguntou, a mais de 100 paulistanos (homens e mulheres de diversas idades, diferentes orientações sexuais, graus de escolaridade e classes sociais): "[...] o que chama a sua atenção, na fala de um homem, no sentido de fazer você pensar que ele possa ser "gay'?" (Observe-se que a mesma pergunta poderia ser feita no sentido de obter pistas acerca do que define uma fala avaliada/ percebida como paulistana, como interiorana etc).

Preparado para a dificuldade em identificar marcas ou fatos linguísticos que seus interlocutores pudessem perceber como índices de uma orientação gay, o pesquisador havia previamente gravado cinco leituras de um texto, por cinco homens diferentes. Após alguns minutos de conversa que sucederam aquela pergunta inicial, reproduziu-se a gravação das cinco leituras do tal texto para cada um dos entrevistados e pediu-se, então, a cada um deles, que atribuíssem uma "nota" de 1 a 5 para cada uma delas: a nota 1 deveria ser atribuída à leitura que julgassem soar "menos gay", enquanto que a nota 5 deveria ser atribuída àquela que julgassem soar "mais gay". A cada leitura deveria ser atribuída uma nota diferente.

Houve grande convergência a respeito de quais leituras soaram "mais gay". Ilustra-se, desse modo, que a percepção que os sujeitos de uma comunidade de fala têm acerca da produção linguística pode ser bastante homogênea (CAMPBELLKIBLER, 2008, 2009), apesar da heterogeneidade da produção. Além disso, após ouvir e avaliar as leituras, os entrevistados puderam justificar-se: diferentemente daquilo que se observou ao início das conversas com esses mais de cem paulistanos, vários deles, após a avaliação das leituras, mostraram-se capazes de levantar hipóteses sobre quais fatos linguísticos haviam chamado sua atenção, no sentido de quais notas atribuiriam a quais leituras.

As apreciações de natureza linguística mais mencionadas pelos entrevistados foram: (i) "certas vogais parecem mais longas"; (ii) "a entonação 'sobe e desce' muito"; (iii) "as palavras são mais cuidadosamente pronunciadas, gays falam mais 'direitinho', cometem menos 'erros'"; (iv) "homens gays e mulheres parecem usar diminutivos de maneira exagerada". Apesar da metalinguagem - essas observações linguísticas estão aqui transcritas do modo como mais frequentemente foram enunciadas -, é inegável que essas descrições são bastante sofisticadas, especialmente considerando-se que, em princípio, os entrevistados não se haviam mostrado capazes de apontar fatos linguísticos que os levassem à interpretação de que o sujeito-falante pudesse ser gay.

Todos esses supostos índices - depreendidos experimentalmente - são convites para análises sociolinguísticas. As duas últimas parecem especialmente instigantes: em nenhuma das leituras (todas de um mesmo texto) havia "erros" que 
permitissem a avaliação de que uma performance teria sido "mais certinha" que outra; em nenhuma das leituras ocorreu emprego de diminutivos. Isso significa que as justificativas em (iii) e (iv) acima, para as notas atribuídas pelos entrevistados às cinco leituras, não foram formuladas de fato com base na audição delas, mas sim com base em percepções e avaliações de natureza sociolinguística que os entrevistados trouxeram das suas vidas. Verificar se essas avaliações encontram correlato nas produções linguísticas é o desafio a se assumir - um desafio, sobretudo, porque pressuporia, idealmente, o trabalho com categorias sociais em constante construção (em vez de categorias pré-estabelecidas - homem, mulher; pobre, rico; gay, heterossexual; paulistano, interiorano etc.).

Numa tentativa de propiciar estudos sobre a correlação entre performance linguística e categorias de sexo/gênero, levando-se em conta o axioma do estilo, Soriano (2012) está trabalhando na coleta de dados da fala de informantes que se voluntariam a gravar suas próprias falas, durante longos períodos (que ultrapassam os limites das entrevistas sociolinguísticas conforme comumente conhecidas), em diferentes momentos e situações, com diferentes interlocutores. Basicamente, a pesquisadora oferece um gravador de fácil portabilidade a informantes selecionados, que o deixam indefinidamente ligado, ao longo de um dia. É evidente que uma coleta de dados feita dessa forma pressupõe um árduo trabalho de edição daquilo que é gravado, antes de ser descrito: partes cuja qualidade acústica é baixa precisam ser descartadas e, mais importante que isso, um termo de consentimento entre a pesquisadora e seus sujeitos-informantes prevê que não se tornem públicas informações pessoais que evidenciem sua identidade. Apesar das dificuldades, contudo, trata-se de um trabalho que poderá permitir estudos inovadores na área de identidades sociais, na sua relação com usos linguísticos.

\section{Classe social}

Atenta ao alargamento da classe média brasileira e à reconfiguração dos grupos sociais que compõem cada estrato socioeconômico (SOUZA; LAMOUNIER, 2010), Faria (2012) propõe-se, em sua iniciação científica, a discutir e estabelecer critérios que possibilitem incluir a variável classe social em futuros estudos sociolinguísticos na cidade de São Paulo.

Partindo da consideração de que os estratos socioeconômicos definidos com base numa comunidade nem sempre são aplicáveis a outras (ASH, 2004), Faria (2012) lança-se ao trabalho de verificar as percepções que os habitantes da capital paulista têm a respeito da estratificação socioeconômica dentro da cidade em que moram. Para tanto, vem-se realizando a coleta de entrevistas voltadas especificamente a investigar quais são as camadas sociais e de que modo os paulistanos estão distribuídos nelas. Além disso, seu projeto prevê a aplicação 
de um questionário a outro grupo de paulistanos, cujas perguntas deverão incidir sobre os critérios que tiverem aparecido na pesquisa sobre avaliação social (possivelmente nível de escolaridade, ocupação profissional, renda, ocupação e escolaridade dos pais/cônjuge, quantidade de dependentes, posse da habitação e bairro). A partir dessa discussão, deverá ser possível formular critérios, ancorados nas percepções de paulistanos sobre as diferenciações socioeconômicas que compõem a sua comunidade, que poderão ser aplicados em novos estudos sociolinguísticos sobre a cidade de São Paulo.

\section{Considerações finais e trabalhos futuros}

Este artigo traçou um panorama dos trabalhos que vêm sendo desenvolvidos pelo GESOL-USP no sentido de consolidar a cidade de São Paulo no mapa de estudos sociolinguísticos brasileiros. A construção de uma nova amostra - as 60 entrevistas do Projeto SP2010 financiado pela FAPESP - está no centro das atividades do grupo, que paralelamente vem desenvolvendo trabalhos de análise de variáveis linguísticas (a partir da Amostra SP-Piloto) e vem delineando caminhos para estudos futuros.

Entre esses caminhos, já começam a ser trilhados aqueles que preveem a inclusão da participação de imigrantes na constituição sociolinguística da cidade. Há projetos em formulação que intencionam focalizar os descendentes de imigrantes árabes, italianos e japoneses, cuja descrição sociolinguística deverá possibilitar comparações interessantes com pesquisas etnolinguísticas desenvolvidas especificamente em outras cidades, como é o caso de Toronto (HOFFMAN; WALKER, 2010). Além disso, uma vez finalizado o Projeto SP2010, pretende-se, como próximo passo, propor a ampliação da amostra, com a inclusão da fala de migrantes, sobretudo nordestinos, cuja presença é tão marcante na cidade, de modo a fornecer uma descrição mais abrangente dessa complexa comunidade.

\section{Agradecimentos}

A todos os membros do GESOL-USP que trabalharam na Amostra SP-Piloto, sem os quais nenhum dos trabalhos aqui reportados teriam se concretizado: Alexandre Sobreiro, Andressa Serena, Camila Barbosa Faria, Dayane Celestino de Almeida, Larissa Soriano, Ivanete Nascimento, Mariane Esteves Bieler, Melissa Cruz e Rafael Stoppa Rocha.

O Grupo todo agradece à FAPESP, com cujos auspícios a construção da Amostra SP2010 se tornou possível. 
MENDES, R. B.; OUSHIRO, L. Paulistanos in Brazilian sociolinguistics map. Alfa, São Paulo, v.56, n.3, p.963-991, 2012.

- ABSTRACT: This paper reports on the activities developed by the Study and Research Group on Sociolinguistics at the University of São Paulo. Aiming at positioning the city of São Paulo and its inhabitants, the Paulistanos (born and raised in this city), in the map of Brazilian Sociolinguistics, the group's works revolve mainly around the ongoing construction of a representative sample of Paulistano speech, which main goal is to answer the questions: "what does it mean to sound like a Paulistano?" and "which variables and variants characterize the Paulistano speech?". This new sample (SP2010) is to be made available (audio and transcriptions) on the Internet to the linguists' community. In addition to discussing the criteria that define such sample, this paper also addresses the challenges involved in its constitution. Moreover, it offers an overview of the researches that have been developed by utilizing the data (SP-Pilot) that was gathered in the preparation and training of the young sociolinguists that would work in the group. Finally, this paper also outlines paths for future work.

- KEYWORDS: Language variation. Paulistanos. Identity. Corpus.

\section{REFERÊNCIAS}

ASH, S. Social class. In: CHAMBERS, J. K.; TRUDGILL, P.; SCHILLING-ESTES, N. (Ed.). The handbook of language variation and change. Oxford: Blackwell, 2004. p.402-422.

BELL, A. Styling the other to define the self. Journal of Sociolinguistics, Hoboken, v.4, p.523-541, 1999.

Language style as audience design. Language in Society, Cambridge, v.13, p.145-204, 1984.

CALLOU, D. M. I.; MORAES, J. A. A norma de pronúncia do /s/ e /r/ pós-vocálico: distribuição por áreas regionais. In: CARDOSO, S. (Org.). Diversidade linguística e ensino. Salvador: Ed. Da UFBA, 1996. p.133-147.

CAMPBELL-KIBLER, K. The nature of sociolinguistic perception. Language Variation and Change, Cambridge, v.21, p.135-156, 2009.

. I'll be the judge of that: diversity in social perceptions of (ING). Language in Society, Cambridge, v.37, n.5, p.637-659, 2008.

CASTILHO, A. T. . Português Brasileiro: descrição, história, teorização.. Lingüistica (Madrid), v. 24, p. 77-100, 2010

. Projeto para a história do português paulista. 2007. Projeto temático de equipe 06/5594-0 apresentado a FAPESP, Universidade de São Paulo, São Paulo, 2007.

CASTILHO, A. T. de; PRETI, D. (Ed.). A linguagem falada culta na cidade de São Paulo: materiais para seu estudo. São Paulo: T.A. Queiroz, 1987. (Diálogos entre dois informantes, v.2). 
. A linguagem falada culta na cidade de São Paulo: materiais para seu estudo. São Paulo:T.A. Queiroz, 1986. (Elocuções formais, v.1).

CHAMBERS, J. K. Studying language variation: an informal epistemology. In: CHAMBERS, J. K.; TRUDGILL, P.; SCHILLING-ESTES, N. (Ed.). The handbook of language variation and change. Oxford: Blackwell, 2004. p.03-14.

Sociolinguistic theory. Oxford: Blackwell, 1995.

CHAMBERS, J. K.; TRUDGILL, P.; SCHILLING-ESTES, N. (Ed.). The handbook of language variation and change. Oxford: Blackwell, 2004.

CHESHIRE, J. Syntactic variation and beyond: gender and social class variation in the use of discourse-new markers. Journal of Sociolinguistics, Hoboken, v.9, n.4, p.479-508, 2005.

CIANCIO, R. Estudo sociolinguístico da fala paulistana por falantes do Itaim Bibi. 2012. Projeto de Iniciação Científica apresentado ao CNPq, Universidade de São Paulo, São Paulo, 2012.

COELHO, R. F. É nóis na fita! Duas variáveis linguísticas numa vizinhança da periferia paulistana: o pronome de primeira pessoa do plural e a marcação de plural no verbo. 2006. 178f. Dissertação (Mestrado em Linguística) - Faculdade de Filosofia, Letras e Ciências Humanas, Universidade de São Paulo, São Paulo, 2006.

DURANTI, A. Linguistic anthropology: history, ideas, issues. In: DURANTI, A. (Ed.). Linguistic anthropology: a reader. Oxford: Blackwell, 2001. p.01-60.

ECKERT, P. Style and social meaning. In: ECKERT, P.; RICKFORD, J. Style and sociolinguistic variation. Cambridge: Cambridge University Press, 2001. p. 119-126.

(ay) goes to the city - Exploring the expressive use of variation. In: GUY, G. R. et al. Towards a social science of language: papers in honor of William Labov. Amsterdam: John Benjamins, 1996. p. 47-68. (Variation and change in Language and Society, v.1).

ECKERT, P.; MCCONNEL-GINET, S. Think practically and look locally. Annual Review of Anthropology, Palo Alto, v.21, n.21, p.461-90, 1992.

FARIA, C. B. de. Para a inclusão de "classe social" nos estudos sociolinguísticos em São Paulo. 2012. Projeto de Iniciação Científica, Universidade de São Paulo, São Paulo, 2012.

GILES, H.; POWESLAND, P.F. Accommodation theory. In: COUPLAND, N.; JAWORSKI, A. (Ed.). A sociolinguistics reader. Macmillan: Basingstoke, England, 1997. p.232-239.

GONÇALVES, S. C. L. O português falado na região de São José do Rio Preto: constituição de um banco de dados anotado para o seu estudo. 2003. Projeto de 
Pesquisa apresentado à FAPESP, Universidade Estadual Paulista, São José do Rio Preto, 2003. Disponível em: <www.iboruna.ibilce.unesp.br/histórico/Projeto>. Acesso em: 15 out. 2012.

GUY, G. R. The sociolinguistic types of language change. Diachronica, Amsterdã, v.7, n.1, p.47-67, 1990.

HOFFMAN, M.; WALKER, J. Ethnolects and the city: ethnic orientation and linguistic variation in toronto english. Language Variation and Change, Cambridge, v.22, p.37-67, 2010.

HOLMES, J.; MEYERHOFF, M. (Ed.). The handbook of language and gender. Oxford: Blackwell, 2005

HORA, D. da (Org.). Estudos sociolinguísticos: perfil de uma comunidade. Santa Maria: Palotti, 2004.

HORNIK, K. R. FAQ. Disponível em: <http://cran.r-project.org/doc/FAQ/R-FAQ. html>. Acesso em: 10 abr. 2011.

HYMES, D. On communicative competence. In: BRUMFIT, C. J.; JOHNSON, K. (Ed.). The communicative approach to language teaching. Oxford: Oxford University Press, 1991. p.5-26.

IBGE. Censo demográfico 2010: resultados gerais da amostra. Brasília, 2010. Disponível em <ftp://ftp.ibge.gov.br/Censos/Censo_Demografico_2010/ Resultados_Gerais_da_Amostra/resultados_gerais_amostra.pdf >. Acesso em: 15 out. 2012.

ITAIM BIBI. Encontra Itaim. São Paulo, [2011]. Disponível em: <http://www. encontraitaim.com.br/>. Acesso em: 20 jan. 2011.

LABOV, W. The social stratification of english in New York city. 2.ed. New York: Cambridge University Press, 2006.

. Principles of linguistic change: social factors. Oxford: Blackwell, 2001a. . The anatomy of style-shifting. In: ECKERT, P.; RICKFORD, J. R. (Ed.). Style and sociolinguistic variation. Cambridge: Cambridge University Press, 2001b.

. Principles of linguistic change: internal factors. Oxford: Blackwell, 1994.

. Where does the sociolinguistic variable stop? a response to Beatriz Lavandera. Working papers in sociolinguistics, Austin, v.44, p.01-22, 1978.

1972.

. Sociolinguistic patterns. Philadelphia: University of Pennsylvania Press,

LAVANDERA, B. Where does the sociolinguistic variable stop? Language in Society, Cambridge, v.7, p.171-182, 1978. 
MENDES, R. B. Gênero/sexo, Variação linguística e intolerância. In: BARROS, D. L. P. de. (Org.). Preconceito e intolerância: reflexões linguístico-discursivas. São Paulo: Mackenzie, 2011a. p.01-30.

. A pronúncia retroflexa do /-R/ na fala paulistana. In:HORA, D. da; NEGRÃO, E. V. (Ed.). Estudos da linguagem: casamento entre temas e perspectivas. João Pessoa: Ideia, 2011b. p.283-300.

What is 'gay speech' in São Paulo, Brazil. In: SANTAEMILIA, J. et al. (Org.). International perspectives on gender and language. València: Universitat de València, 2007. p.296-305.

MENDES, R. B.; OUSHIRO, L. Production and perception of retroflex/r/in São Paulo Portuguese. 2011. Trabalho apresentado ao Variation and Language Processing, United Kingdom, 2011a.

Percepções sociolinguísticas sobre as variantes tepe e retroflexa na cidade de São Paulo. In: HORA, D.; NEGRÃO, E. V. (Org.). Estudos da linguagem: casamento entre temas e perspectivas. João Pessoa: Ideia, 2011b. p.262-281.

MILROY, L. Social networks. In: CHAMBERS, J. K.; TRUDGILL, P.; SCHILLINGESTES, N. (Ed.). The handbook of language variation and change. Oxford: Blackwell, 2004. p.573-600.

Language and social networks. Oxford: Basil Blackwell, 1980.

MONARETTO,V. N. de O. Um estudo da vibrante: análise variacionista e fonológica. 1997. 145f. Tese (Doutorado em Letras) - Pontifícia Universidade Católica do Rio Grande do Sul, Porto Alegre, 1997.

NASCIMENTO, I. B. do. O uso variável do pronome de segunda pessoa você(S)/ Cê(S) na cidade de São Paulo. 2011. 217f. Dissertação (Mestrado em Linguística) - Faculdade de Filosofia, Letras e Ciências Humanas, Universidade de São Paulo, São Paulo, 2011.

OCHS, E. Indexing gender. In: DURANTI, A.; GOODWIN, C. Rethinking context. Cambridge: Cambridge University Press, 1991. p.335-358.

OUSHIRO, L. Uma análise variacionista para as interrogativas-O. 2011. 160f. Dissertação (Mestrado em Linguística) - Faculdade de Filosofia, Letras e Ciências Humanas, Universidade de São Paulo, São Paulo, 2011a.

Identidade na pluralidade: produção e percepção linguística na cidade de São Paulo. Projeto de doutorado apresentado a FAPESP/Processo 2011/09122-6, Universidade de São Paulo, São Paulo, 2011b.

Wh-interrogatives in Brazilian Portuguese: the influence of common ground. University of Pennsylvania Working Papers in Linguistics, Pennsylvania, v.17, n.2, p.145-154, 2011c. 
PRETI, D.; URBANO, H. (Ed.). A linguagem falada culta na cidade de São Paulo: materiais para seu estudo. São Paulo:T.A. Queiroz, 1988. (Entrevistas, v.3).

PRETI, D.; URBANO, H. (Ed.) A linguagem falada culta na cidade de São Paulo: materiais para seu estudo. São Paulo: T.A. Queiroz, 1990. (Estudos, v.4).

ROCHA, R. S. Negação pós-verbal no português paulistano: restrições discursivopragmáticas. In: CONGRESSO INTERNACIONAL DE LINGUÍSTICA HISTÓRICA, 2., 2012, Resumos... São Paulo: Universidade de São Paulo, São Paulo, 2012a.

- Verbal negative structures in paulistano portuguese. 2012. Trabalho apresentado no International GSCP Conference: Speech and Corpora, Belo Horizonte, 2012b.

RODRIGUES,A. C. S. Fotografia sociolinguística do português do Brasil: o português popular em São Paulo. In: CASTILHO, A. T. (Ed.). História do português paulista. Campinas: Instituto de Estudos da Linguagem/UNICAMP, 2009. p.151-158.

A concordância verbal no português popular em São Paulo. 1987. 266 f. Tese (Doutorado em Letras) - Faculdade de Filosofia, Letras e Ciências Humanas, Universidade de São Paulo, São Paulo, 1987.

SÃO PAULO (Cidade). Prefeitura de São Paulo. Município em mapas: político administrativo. São Paulo, 2011. Disponível em: <http://sempla.prefeitura.sp.gov. br/mm/panorama/>. Acesso em: 20 mar. 2011.

. Histórico. São Paulo, [2011]. Disponível em: <http://www.prefeitura.sp.gov. br/cidade/secretarias/subprefeituras/pinheiros/historico/index.php?p=472>. Acesso em: 20 jan. 2011.

SILVA, F. G. Concordância nominal: um contraste dentro da cidade de São Paulo. Projeto de Mestrado apresentado ao Departamento Linguística, Universidade de São Paulo, São Paulo, 2011.

SOUZA, A.; LAMOUNIER, B. A classe média brasileira: ambições, valores e projetos de sociedade. São Paulo: Elsevier, 2010.

SORIANO, L. Estudo sociolinguístico de gays paulistanos em diferentes situações de fala. 2012. Projeto de Iniciação Científica, Universidade de São Paulo, São Paulo, 2012.

STALNAKER, R. Common ground. Linguistics and Philosophy, Dordrecht, v.25, p.701-721, 2002.

TAGLIAMONTE, S. A. Analysing sociolinguistic variation. São Paulo: Cambridge University Press, 2006. 
TRUDGILL, P. The social stratification of English in Norwich. Cambridge: Cambridge University Press, 1974.

VIEIRA, M. Entre São Paulo (SP) e Campo Grande (MS): fatos discursivopragmáticos no uso de variantes morfossintáticas. 2012. Projeto de Doutorado apresentado ao departamento Linguística, Universidade de São Paulo, São Paulo, 2012.

Recebido em maio de 2012

Aprovado em agosto de 2012 